\title{
Numerical simulation of the effect of rain on aerodynamic performance and aeroacoustic mechanism of an airfoil via a two-phase flow approach
}

\author{
Hossein Fatahian ${ }^{1}$ D $\cdot$ Hesamoddin Salarian ${ }^{1} \cdot$ Majid Eshagh Nimvari ${ }^{2}$ Jahanfar Khaleghinia ${ }^{1}$
}

Received: 16 January 2020 / Accepted: 2 April 2020 / Published online: 9 April 2020

(c) Springer Nature Switzerland AG 2020

\begin{abstract}
In the present study, two complex physical phenomena have been completely simulated and discussed in detail to predict the aerodynamic degradation and aeroacoustic mechanism of a NACA 0012 airfoil in both dry and heavy rain conditions. For this purpose, a CFD-based multiphase model was adopted to numerically investigate the process of formation of the water film layer on the airfoil surface by coupling the Lagrangian Discrete Phase Model (DPM) and the Eulerian Volume of Fluid (VOF) models. The Ffowcs Williams-Hawkings (FW-H) method was used to predict the aerodynamic noise of the airfoil in a heavy rain condition. The results showed that there were significant degradations of the airfoil aerodynamic performance because of water film formation especially at lower angles of attack. The maximum value of lift-to-drag ratio degradation was $56 \%$ at the angle of attack of $2^{\circ}$. Also, the Sound Pressure Level (SPL) increased due to the rain condition. The SPL was sensitive to the raindrop impact on airfoil surface and caused to increase SPL especially in the frequency region less than $2000 \mathrm{~Hz}$. By increasing the angle of attack, the SPL increased especially in the high-frequency region higher than $2500 \mathrm{~Hz}$ in rain condition.
\end{abstract}

Keywords Eulerian-lagrangian · Heavy rain · Aerodynamic degradation · Aeroacoustic · Sound pressure level (SPL)

\section{Nomenclature}

$\mu \quad$ Air dynamic viscosity

c Airfoil chord length

a Angle of attack

$\rho_{D} \quad$ Density of droplets

$\rho \quad$ Density of fluid phase

$\gamma^{+} \quad$ Dimensionless wall distance

$\delta(f) \quad$ Dirac delta function

$\varepsilon \quad$ Dissipation rate

$C_{D} \quad$ Drag coefficient

$\beta \quad$ Drag force

$\mu_{T} \quad$ Eddy viscosity

$u_{\mathrm{n}} \quad$ Flow velocity normal to the surface $(f=0)$

$u_{i} \quad$ Fluid phase velocity in i direction

$g_{i} \quad$ Gravitational acceleration

$\mathrm{H}(\mathrm{f}) \quad$ Heaviside function
$E_{\text {im }} \quad$ Impact energy

$C_{L} \quad$ Lift coefficient

$M_{\text {ex }} \quad$ Momentum exchange

NACA National Advisory Committee for Aeronautics

$\mathrm{u}_{\mathrm{p}} \quad$ Parcel phase velocity in i direction

$P \quad$ Pressure

Re Reynolds number

$C_{f} \quad$ Skin friction coefficient

$\sigma_{w} \quad$ Surface tension of water

$v_{n} \quad$ Surface velocity component normal to the surface

$v_{i} \quad$ Surface velocity in i direction

$\mathrm{U}_{\mathrm{T}} \quad$ Terminal velocity

$p^{\prime} \quad$ The far-field sound pressure

$\mathrm{T}_{\mathrm{ij}} \quad$ The Lighthill tensor

$a_{0} \quad$ The sound velocity in the far-field

Hossein Fatahian, fatahianhossein@gmail.com | 'Department of Mechanical Engineering, Nour Branch, Islamic Azad University, Nour, Iran. ${ }^{2}$ Faculty of Engineering, Amol University of Special Modern Technologies, Amol, Iran. 


$\begin{array}{ll}\delta_{b l} & \text { Thickness of the boundary layer } \\ \mathrm{t} & \text { Time } \\ \mathrm{k} & \text { Turbulent kinetic energy }\end{array}$

\section{Introduction}

The aerodynamic penalty of aircraft flying in heavy rain has been considered as a major cause of many severe aviation crashes in rain conditions $[1,2]$. The rainfall at the rate of $1800 \mathrm{~mm} / \mathrm{h}$ leads to decrease by $30 \% \mathrm{in} \mathrm{lift}$ and about $20 \%$ increase in drag [2]. Also, this rate can affect the boundarylayer separation, the stall angle of attack, flight safety and aircraft maneuverability [1,3]. Drop impact dynamics on surfaces and liquid films have been a continuing important topic in the fields of fundamental fluid mechanics [4] and practical aerospace engineering $[5,6]$. Consideration of the rain effect on aircraft flight has begun with a wind tunnel test which was done by Rhode [7]. He found that heavy rain exposure time is not enough to induce aircraft to the ground. Haines and Luers $[8,9]$ investigated the heavy rain penalties on aircraft and found that the heavy rain causes the roughening of the wing which caused to decrease in stall angle and also the decrease in lift about 30\%. Wan and $\mathrm{Wu}[10]$ also numerically simulated the heavy rain effect on the airfoil. The water film layer and vertical rain mass flow rate on the airfoil upper surface were added which caused to increase the airfoil roughening effects. Wu et al. [11] numerically studied a transport-type airfoil, NACA 64-21, exploring the aerodynamic penalties and mechanisms which affect airfoil performance in heavy rain conditions. They concluded that the $C_{L}$ decreased by maximum $13.2 \%$ and the $C_{D}$ increased by maximum $47.6 \%$. The effects of heavy rain on the aerodynamic efficiency of the NACA 0012 airfoil were investigated by Ismail et al. [12]. Their results demonstrated a remarkable increase in drag and a decrease in lift in heavy rain condition. Wu [13] studied the drop impact on the airfoil surface in the natural drop-laden two-phase flow environment. He found that the adverse effects of water can be reflected by lift loss and drag increase. Moreover, other movement forms, e.g. drop oscillation, can also change the effects of water on airfoil performance.

Stringent regulations on noise radiated by aircraft engines are getting tighter, and this is due to the forecast of future explosive growth in air transport that requires special attention in reducing noise emissions, especially during landing approaches in airport-neighboring communities [14]. Hence, knowledge of noise sources and mechanisms of noise generation at the trailing edge of an airfoil is getting high priority for addressing and mitigating aircraft noise emissions [14]. Recently, the interest in computational acoustics has increased and numerical simulation of airfoil acoustic is a new research topic in dry condition. Brooks et al. [15] reviewed the self-generated noise mechanisms associated with subsonic flow surrounding an airfoil. Singer et al. [16] applied the Reynolds-Averaged Navier-Stokes (RANS) equations and the Ffowcs Williams-Hawkings (FW-H) acoustic analogy to study the sound produced by a bluff-body vortex generator located near the sharp trailing edge of a two-dimensional airfoil. Shen et al. [17] used the flow acoustics splitting approach to calculate the aero-acoustic of the flow field around a NACA 0015 airfoil. They used large eddy simulation for obtaining the instantaneous flow quantities. In their study, a parametric investigation of the noise pattern for various angles of attack demonstrated that the noise level raised with increasing angles of attack. Ghasemian and Nejat [18] investigated the aerodynamic noise from the flow field around a NACA 0012 airfoil. Also, the effect of observer position on the overall sound pressure level (OASPL) was considered and their results indicated that the OASPL varied logarithmically with the receiver distance, as was expected. Jackson and Dakka [14] considered trailing edge noise and shear noise for a NACA 0012 airfoil, focusing on noise mechanisms at the trailing edge to notice and realize sources of noise generation. They concluded that when the angle of attack increased, shear noise contributes less energy further downstream of the airfoil.

Many researchers have investigated airfoil acoustic mechanisms and noise production in dry condition. To the best of our knowledge, any study has not been conducted yet to simulate and predict the noise production over an airfoil in a heavy rain condition. In the present study, two different approaches were combined to simulate the aerodynamic performance and aeroacoustic mechanism of an airfoil in dry and rain conditions. First, a two-way momentum coupled Eulerian-Lagrangian approach was applied to investigate the aerodynamic performance of a NACA 0012 airfoil in a heavy rain condition. Second, the Ffowcs Williams-Hawkings (FW-H) method [19] was used to predict the far-field noise in a heavy rain condition. Also, the aeroacoustic and aerodynamic performances were computed numerically and discussed in detail with focusing on the effect of accumulation of water on airfoil surfaces at various angles of attack. Finally, aeroacoustic and aerodynamic results in dry and rain conditions are both assessed and discussed. The outcome of the present study may provide a useful computational result for the aviation community and realistic aeronautical applications to have a better understanding of both aeroacoustic and aerodynamic performances in dry and rain conditions. 


\section{Computational procedure}

\subsection{Rain modeling}

The intensity of heavy rain is usually necessary to measure in the simulation of rain. A rainfall rate of $100 \mathrm{~mm} / \mathrm{h}$ or higher is supposed as heavy rain [20]. In both numerical and experimental work, the correlation between rainfall rate $R(\mathrm{~mm} / \mathrm{h})$ and liquid water content $L W C\left(\mathrm{~g} / \mathrm{m}^{3}\right)$ is commonly defined by Bezos et al. [21]:

For heavy rain or thunderstorm is written as:

$L W C=0.054 R^{0.84}$

For light rain is written as:

$L W C=0.0889 R^{0.84}$

Also, the velocity of the rain particles falling on the airfoil surface is necessary to be computed. The uniform velocity of rain particles before contacting the airfoil surface is called terminal velocity $\left(U_{T}\right)$. This velocity varies with particles diameter and can be written as [22]:

$U_{T}=9.58\left(\left\{1-\exp \left[-\frac{D_{P}^{1.147}}{1.77}\right]\right\}\right)$

where $D_{p}$ is the diameter of the rain particle.

\subsection{Continuous phase}

In the present study, a coupled Eulerian-Lagrangian method is implemented to simulate the water-layer formation on the airfoil due to rain. The continuum conservation equations are solved by the Eulerian-Lagrangian approach for the continuous phase and the Lagrangian equations of motion for the discrete phase are integrated which is defined as the Discrete Phase Model (DPM) [23]. The Unsteady Reynolds Averaged Navier-Stokes equations (URANS) of mass and momentum are solved with the $k-\varepsilon$ standard turbulence model to solve the flow field around the airfoil. This model is recommended by previous researches which has good accuracy for modeling turbulent flow over an airfoil in a heavy rain condition using a two-phase flow approach [3, 24-27].

The governing equations are defined as:

Conservation equation of mass:

$\frac{\partial \rho}{\partial t}+\frac{\partial}{\partial x i}\left(\rho \bar{u}_{i}\right)=0$

Conservation equation of momentum:

$$
\begin{aligned}
& \frac{\partial}{\partial t}\left(\rho \bar{u}_{i}\right)+\frac{\partial}{\partial x_{j}}\left(\rho{\overline{u_{j}}}_{i}\right)=-\frac{\partial \bar{P}}{\partial x_{i}} \\
& \quad+\frac{\partial}{\partial x_{j}}\left[\mu\left(\frac{\partial \bar{u}_{i}}{\partial x_{j}}+\frac{\partial \bar{u}_{j}}{\partial x_{i}}-\rho \overline{u_{j}^{\prime} u^{\prime}}{ }_{i}\right)\right]-M_{e x_{i}}
\end{aligned}
$$

where $-\rho \overline{u_{j}^{\prime} u^{\prime}}$ defines the Reynolds stress. $\rho, \bar{u}_{i}$ and $\mu$ are the air density, mean part of the velocity component and the air dynamic viscosity, respectively. $u_{i}^{\prime}$ is the fluctuating part of the velocity components. denotes the component of interphase momentum exchange $M_{e_{i}}$ vector (referred to in Eq. (18) in the $i$ direction.

The equations of k-epsilon standard turbulence model are given by [28]:

$$
\begin{aligned}
& \frac{\partial(\rho k)}{\partial t}+\frac{\partial\left(\rho k u_{i}\right)}{\partial x_{i}}=\frac{\partial}{\partial x_{j}}\left[\frac{\mu_{t}}{\sigma_{k}} \frac{\partial k}{\partial x_{j}}\right]+2 \mu_{t} E_{i j} E_{i j}-\rho \varepsilon \\
& \frac{\partial(\rho \varepsilon)}{\partial t}+\frac{\partial\left(\rho \varepsilon u_{i}\right)}{\partial x_{i}}=\frac{\partial}{\partial x_{j}}\left[\frac{\mu_{t}}{\sigma_{\varepsilon}} \frac{\partial \varepsilon}{\partial x_{j}}\right]+C_{1 \varepsilon} \frac{\varepsilon}{k} 2 \mu_{t} E_{i j} E_{i j}-C_{2 \varepsilon} \rho \frac{\varepsilon^{2}}{k}
\end{aligned}
$$

where $E_{i j}$ and $u_{i}$ are the component of the rate of deformation and the velocity component, respectively. $\mu_{t}=\rho C_{\mu} \frac{k^{2}}{\varepsilon}$ is the eddy viscosity. The equations have some adjustable constants $\sigma_{k^{\prime}} \sigma_{\varepsilon,} C_{1 \varepsilon}$ and $C_{2 \varepsilon}$. The values of these constants are as follows [28]:

$C_{\mu}=0.09 \sigma_{k}=1.00 \sigma_{\varepsilon}=1.30 C_{1 \varepsilon}=1.44 C_{2 \varepsilon}=1.92$

\subsection{Discrete phase}

The discrete phase model (DPM) is applied for modeling the raindrops. In DPM, the raindrops are injected in the continuous flow field by using the wall film. In this model, a thin film is formed when the raindrops impinge upon the airfoil surface $[28,29]$. Moreover, raindrops are supposed to be nonevaporating, non-interacting, and non-deforming spheres subject only to the drag and gravity forces [26]. Bilanin [30] justified the assumption of non-interacting droplets. Furthermore, a two-way momentum coupled Eulerian-Lagrangian approach is implemented to simulate the floatation of discrete particles in continuous airflow. The Lagrangian equations of motion for the raindrops are written as [3]:

$\frac{d u_{p}}{d t}=\frac{3 \mu C_{D, p} \operatorname{Re}_{p}}{4 \rho_{p} D_{p}^{2}}\left(u-u_{p}\right)+g$

$\frac{d x_{p}}{d t}=u_{p}$ 
where $x_{p}$ is the position of particles, $u$ and $u_{p}$ are the velocity of the air and the velocity of particles, respectively. $g$ denotes the gravitational acceleration, $\rho_{p}$ is the particle density. $\operatorname{Re}_{p}$ is the particle Reynolds number. Equation (8) is the force balance equation of the particle while Eq. (9) is the correlation between the displacement and particle velocity. $C_{D, P}$ is the particle drag coefficient for which we used the spherical drag law [31]. The drag coefficient $C_{D, P}$ is given by:

$C_{D, P}=\frac{K_{1}}{\operatorname{Re}}+\frac{K_{2}}{\operatorname{Re}^{2}}+K_{3}$

where $K_{1}, K_{2}$ and $K_{3}$ are the parameters dependent on the raindrop impact energy. $\mathrm{Re}_{p}$ is the particle Reynolds number, which is defined as:

$\operatorname{Re}_{p}=\frac{\rho D_{P}\left|u-u_{p}\right|}{\mu}$,

Analytical integration or numerical discretization schemes can be used for solving Eqs. (8) and (9). In our study, the second-order accurate implicit trapezoidal discretization is used which is provided in ANSYS FLUENT 18.2. By applying the trapezoidal discretization:

$u_{p}^{n+1}=u_{p}^{n}+\frac{3 \mu C_{D, p} \operatorname{Re}_{p}}{8 \rho_{p} D_{p}^{2}} \Delta t\left[\left(u^{n}+u^{n+1}\right)-\left(u_{p}^{n}+u_{p}^{n+1}\right)\right]$

$u^{n+1}=u^{n}+\Delta t u_{p}^{n} \cdot \nabla u^{n}$

The ultimate iterative formula for the particle velocity at the new location is attained by substituting Eq. (12) into Eq. (13) written as:

$u_{p}^{n+1}=\frac{u_{p}^{n}\left(1-\frac{3 \mu C_{D, p} \mathrm{Re}_{p}}{8 \rho_{p} D_{p}^{2}} \Delta t\right)+3 \frac{3 \mu C_{D, p} \mathrm{Re}_{p}}{4 \rho_{p} D_{p}^{2}} \Delta t\left(u^{n}+\frac{\Delta t}{2} u_{p}^{n} \cdot \nabla u^{n}\right)}{1-\frac{3 \mu C_{D, p} \mathrm{Re}_{p}}{8 \rho_{p} D_{p}^{2}} \Delta t}$

The new particle location is always calculated by the trapezoidal discretization of Eq. (9):

$x_{p}^{n+1}=x_{p}^{n}+\frac{1}{2} \Delta t\left(u_{p}^{n}+u_{p}^{n+1}\right)$

The wall interaction regimes are computed for drop wall interaction. Stick, rebound, spread, and splash are the four regimes which are depended on the wall temperature and impact energy. The temperature is below the boiling point for present simulation, thus the impingement rain particles can adhere, extend or sputter. The impact energy $E_{i m}$ is written as follows [25]:
$E_{i m}^{2}=\frac{\rho_{w} V_{r}^{2} D_{p}}{\sigma_{w}}\left(\frac{1}{\min \left(h_{0} / D_{p}, 1\right)+\delta_{b l} / D_{p}}\right)$,

where $V_{r}$ denotes the particle velocity relative to wall frames $\left(V_{r}=V_{p}-V_{\text {wall }}\right), \sigma_{w}$ is the surface tension of water, $h_{0}$ is the total height of water film and $\rho_{w}$ is the water density. The thickness of the boundary layer is defined as $\delta_{b l}$.

$\delta_{b l}=\sqrt{\frac{\mu D_{P}}{\rho_{w} V_{r}}}$

When the trajectory of the particle is computed, the momentum added or missed by the particle is followed and the quantity of the particle is embedded in the following continuous phase calculation. Actually, the effect of the continuous phase on the particle trajectory is also embedded in the discrete phase trajectory computation. The two-way coupling process is repeated and solved alternately until a steady state is attained for two phases. The interphase drag forces cause a momentum exchange between two phases. The coupling term of momentum is defined as [3]:

$M_{e x}=\sum \frac{3 \mu C_{D, P} \operatorname{Re}_{p}}{4 \rho_{P} D_{P}^{2}}\left(u-u_{p}\right) \dot{m}_{p} \Delta t$,

where $M_{e x}$ is the momentum change of a particle and $m_{p}$ is the mass flow rate of particle per unit volume. The airflow field in a dry condition is first computed to simulate the rain condition. Then the trajectory of the particle is computed from the velocity field of the air.

In the computation of the particle trajectories, the random walk dispersion model is adopted to consider the turbulence effect in the continuous phase on the particle trajectories. Next, the momentum coupling "body force" term computed by Eq. (18) is appended to the source term of the air momentum equation to calculate the effect of rain droplets on the air phase. This process is repeated in a loop until a steady state is attained for two phases.

\subsection{Aeroacoustic modeling}

The Ffowcs Williams-Hawkings (FW-H) method [32] was used to predict the far-field noise. The $\mathrm{FW}-\mathrm{H}$ equation is the most common form of the Lighthill acoustic analogy [33] and is suitable for the prediction of sound produced by rigid bodies in arbitrary motion. The sound pressure level spectra are computed by Fast Fourier Transform (FFT) at the receiver locations. The reference acoustic pressure is equal to the threshold of human hearing of $2 \times 10^{5} \mathrm{~Pa}$. The basic governing equations of the continuity and momentum are as follows: 
$\frac{D \rho}{D t}+\operatorname{div}(\rho \vec{u})=\frac{\partial \rho}{\partial t}+\frac{\partial\left(\rho u_{i}\right)}{\partial x_{i}}=q$,

where $q$ is the mass production rate per unit volume. The momentum equation was expressed as:

$\frac{\partial\left(\rho u_{i}\right)}{\partial t}+\frac{\partial\left(\rho u_{i} u_{j}\right)}{\partial x_{i}}=-\frac{\partial P}{\partial x_{i}}-\rho g \frac{\partial \tau}{\partial x_{i}}+f_{i}$

where $f_{i}$ represents the body forces. From Eqs. (19) and (20), Eq. (21) was obtained in the following form:

$\frac{\partial^{2} \rho}{\partial t^{2}}+\alpha_{0}^{2} \nabla^{2} \rho=\frac{\partial^{2}\left(T_{i j}\right)}{\partial x_{i} x_{j}}$

Here, $a_{0}$ is the sound speed and $T_{i j}$ is the Lighthill stress tensor. It was expressed as [19]:

$T_{i j}=\rho u_{i} u_{j}+\delta_{i j}\left(p-\rho \alpha_{0}^{2}\right)+\tau_{i j}$

First-term of RHS of Eq. (22) is the turbulence velocity fluctuations (Reynolds stresses), the second term is due to changes in pressure and density, and the third term is due to the shear stress tensor. The $\mathrm{FW}-\mathrm{H}$ theory includes surface source terms in addition to the quadrupole-like source presented by Caridi [34]. The surface sources are commonly referred to as thickness (or monopole) sources and loading (or dipole) sources. This equation was presented as follows [19]: where $\vec{x}$ is the observer position and $t$ is the observer time. $P^{\prime}$ is the acoustic pressure; $P_{T}^{\prime}$ and $P_{L}^{\prime}$ describe the acoustic pressure field resulting from thickness and loading, corresponding to the monopole and the dipole source [35]. By solving this equation, pressure variation and SPL (measured in $\mathrm{dB}$ ) were calculated by Eq. (25) as follows: $\vec{x}$

$S P L=20 \log _{10} \frac{P_{r m s}}{P_{\text {ref }}}$,

where $P_{r m s}$ is the root-mean-square sound pressure and $P_{0}$ is the reference sound pressure, both measured in $\mathrm{Pa}$.

\section{Model description and boundary conditions}

The two-dimensional view of the computational domain was presented in Fig. 1. The inlet had a uniform velocity corresponding to a chord-based Reynolds number (Re) of $3.1 \times 10^{5}$. The outlet was defined as a pressure outlet and the no-slip condition was used on the airfoil surface. The computational domain is large enough to avoid external effects on the airfoil flow field. Three different sizes for the computational domains with diameters equal to 20 , 25 and 30 chords from the leading edge of the airfoil are generated to consider the pressure coefficient $\left(C_{p}\right)$ for domain extent independence test as shown in Fig. 2. This

$$
\begin{aligned}
\frac{1}{\alpha_{0}^{2}} \frac{\partial^{2} p^{\prime}}{\partial t^{2}}-\nabla^{2} p^{\prime}= & \frac{\partial^{2}}{\partial x_{i} \partial x_{j}}\left\{T_{i j} H(f)\right\}-\frac{\partial}{\partial x_{i}}\left\{\left[P_{i j} n_{j}+\rho u_{i}\left(u_{n}-v_{n}\right)\right] \delta(f)\right\} \\
& +\frac{\partial}{\partial t}\left\{\left[\rho_{0} v_{n}+\rho\left(u_{n}-v_{n}\right)\right] \delta(f)\right\}
\end{aligned}
$$

The terms at RHS are named quadrupole, dipole and monopole sources, respectively. $p$ is the sound pressure in the far-field $p^{\prime}=\left(p-p_{0}\right) \cdot u_{n}$ denotes the fluid velocity component normal to the surface, $v_{n}$ denotes the surface velocity component normal to the surface. $u_{i}$ is fluid velocity component in $x_{i}$ direction, and $\alpha a_{0}$ is the sound velocity in the far-field. $T_{i j}$ is the Lighthill stress tensor defined in Eq. (22). Also, $f$ is a function defined based on a surface reference system, $H(f)$ and $\delta(f)$ are Heaviside and Dirac delta functions, respectively.

The wave Equation (Eq. (23)) can be integrated under the assumptions of the free-space flow and the absence of obstacles between the sound sources and the receivers. Acoustic pressure ' which was mentioned in Eq. (23) was composed as follows:

$P^{\prime}(\vec{x}, t)=P_{T}^{\prime}(\vec{x}, t)+P_{L}^{\prime}(\vec{x}, t)$, test is done at an angle of attack of $20^{\circ}$ and Reynolds number $(\mathrm{Re})$ of $3.1 \times 10^{5}$ for baseline airfoil in dry condition. Finally, it is found that a circular region with a diameter of 25 chords from the leading edge of the airfoil is suitable for present simulation.

An injection line ( $I$ ) with 10 chords long was selected which was located 3 chords upstream of the leading edge of the airfoil to inject the rain particles into the computational domain. Four different positions of injection line which were located 1, 2, 3 and 4 chords upstream of the leading edge of the airfoil were selected to find the sufficient distance of this line to represent the airfoil under rain condition. For this purpose, the mass distribution of water film over the airfoil for baseline airfoil in rain condition at $a=20^{\circ}$ is presented in Fig. 3. It was concluded that the injection line which was located 3 chords upstream of the leading edge of the airfoil was far enough for simulation of rain condition. 
Fig. 1 Two-dimensional view of the computational domain
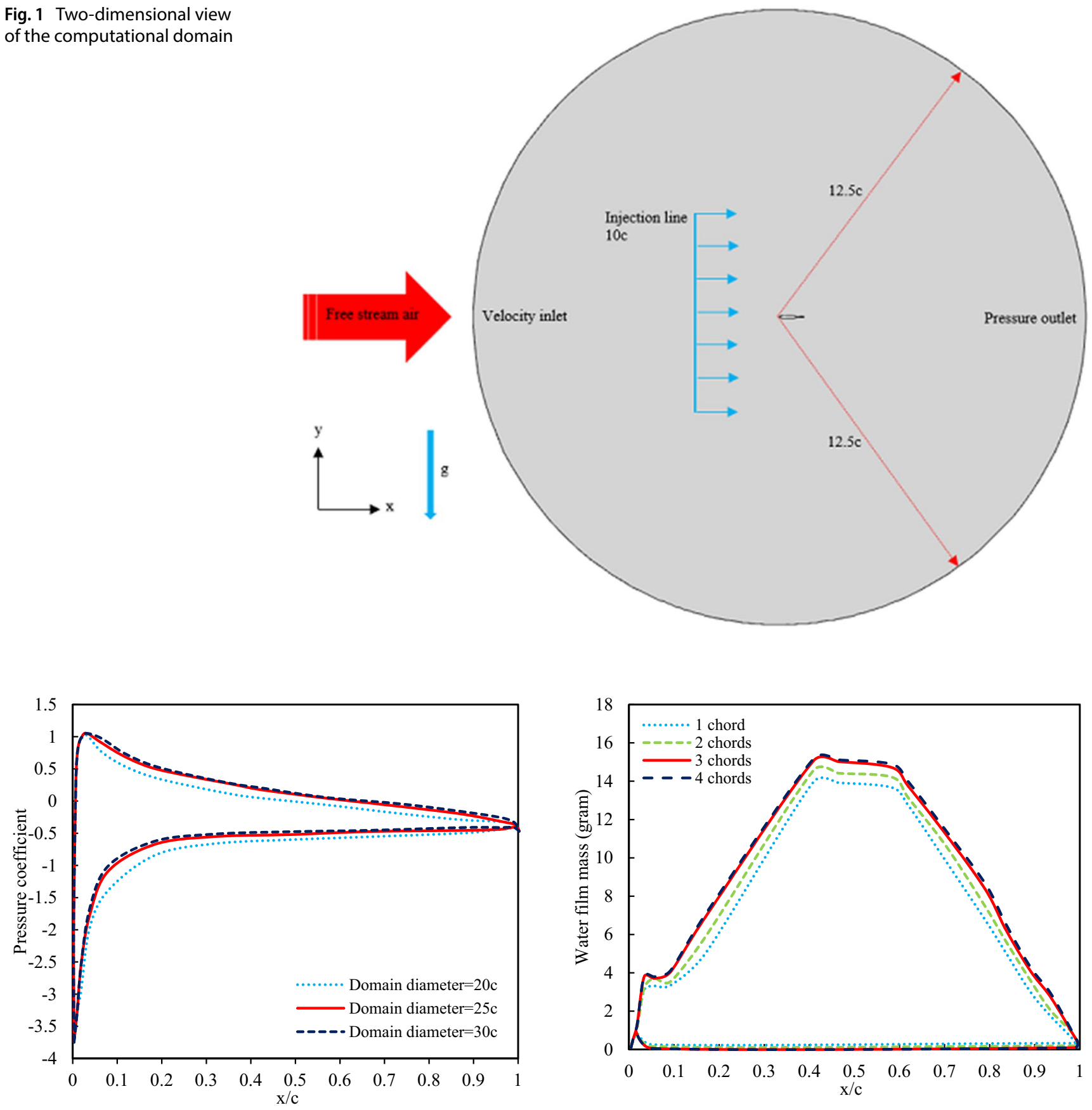

Fig. 3 The position of injection line independence test

Fig. 2 domain extent independence test

\section{Computational grids and grid independence study}

The computational domain was meshed using the structured O-type cells as illustrated in Fig. 4. Four different cells were used to compute lift and drag coefficients in order to examine the grid independence study. Four different grids with cell numbers of 18,000,32,000, 46,000

\section{SN Applied Sciences}

and 65,000 were generated for the NACA 0012 airfoil to consider grid independency. The comparison of lift and drag coefficients between four different cells for LWC of $0 \mathrm{~g} / \mathrm{m}^{3}$ and $30 \mathrm{~g} / \mathrm{m}^{3}$ are shown in Tables 1 and 2, respectively. After considering the grid independence study, it was found that the grid with 46,000 cells was suitable for the present simulation. Versteeg and Malalasekera [28] reported the value of $Y^{+}$should be -1 and the nearwall mesh resolution was determined by this value. As 
Fig. 4 O-type structured mesh

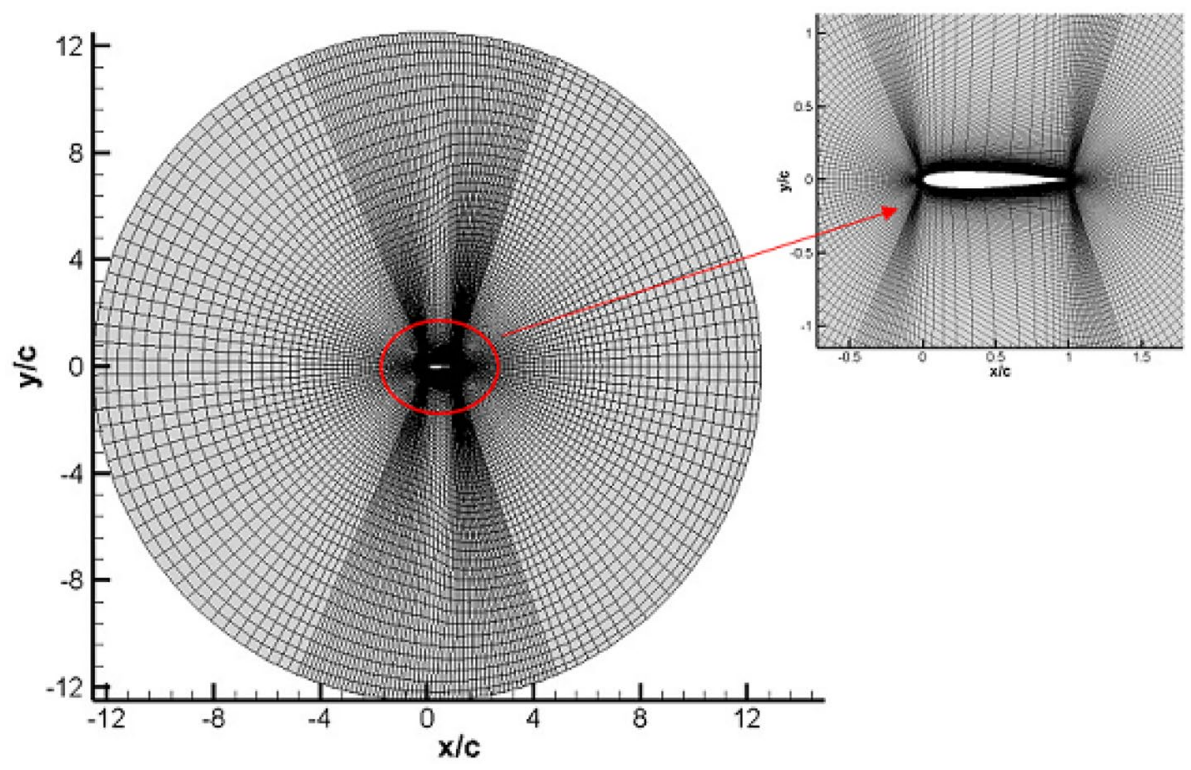

Table 1 Grid independence study for LWC of $0 \mathrm{~g} / \mathrm{m}^{3}$

\begin{tabular}{llllll}
\hline Number of cells & \multicolumn{2}{l}{$a=10^{\circ}$} & & \multicolumn{2}{l}{$a=14^{\circ}$} \\
\cline { 2 - 3 } & $C_{L}$ & $C_{D}$ & & $C_{L}$ & $C_{D}$ \\
\hline 18,000 & 0.922 & 0.095 & & 1.081 & 0.146 \\
32,000 & 0.868 & 0.082 & & 0.951 & 0.134 \\
46,000 & 0.839 & 0.070 & & 0.928 & 0.125 \\
65,000 & 0.837 & 0.068 & & 0.926 & 0.122 \\
\hline
\end{tabular}

Table 2 Grid independence study for LWC of $30 \mathrm{~g} / \mathrm{m}^{3}$

\begin{tabular}{llllll}
\hline Number of cells & \multicolumn{2}{l}{$a=10^{\circ}$} & & $a=14^{\circ}$ & \\
\cline { 2 - 3 } & $C_{L}$ & $C_{D}$ & & & $C_{L}$ \\
\hline 18,000 & 0.882 & 0.109 & & 1.174 & 0.143 \\
32,000 & 0.824 & 0.094 & & 0.962 & 0.131 \\
46,000 & 0.780 & 0.086 & & 0.939 & 0.122 \\
65,000 & 0.777 & 0.083 & & 0.936 & 0.120 \\
\hline
\end{tabular}

shown in Fig. 5, the average $Y^{+}$value, which is the nondimensional normal distance to the airfoil surface from the first grid, is lower than 1 for grid with 46,000 cells. In addition, details of the grid cells and $\mathrm{Y}^{+}$distribution at $a=, 10^{\circ}$ and $\operatorname{Re}=3.1 \times 10^{5}$ are presented in Table 3 .

In most researches, lift coefficient $\left(C_{L}\right)$, drag coefficient $\left(C_{D}\right)$ and lift-to-drag ratio $(L / D)$ are usually adopted for measuring the aerodynamic performance, which can be written as follows:

$C_{L}=\frac{L}{\frac{1}{2} \rho_{a} v_{\infty}^{2} c}$
$C_{D}=\frac{D}{\frac{1}{2} \rho_{a} v_{\infty}^{2} c}$

$\frac{L}{D}=\frac{C_{L}}{C_{D}}$,

where $L$ is the lift, $D$ is the drag, $\rho_{a}$ and $v_{\infty}$ are air density and free stream velocity, $c$ is the airfoil chord length.

\section{Numerical solution and time-step independence study}

In the present study, all flow and acoustic simulations and post-processing calculations of the data were performed with the commercial software ANSYS Fluent 18.2 which is based on the control volume approach. The calculation was based on a pressure-based solver utilizing the implicit body-force treatment to consider the effect of gravity. The Unsteady Reynolds-Averaged Navier-Stokes equations (URANS) were solved using the k-epsilon two-equation turbulence model with enhanced wall treatment. The turbulence intensity was chosen to be less than $0.1 \%$ to consider the low free-stream turbulence level. SIMPLE (Semi-Implicit Method for Pressure Linked Equations) scheme and the PRESTO! (PREssure STaggering Option) scheme was used for pressure-velocity coupling and pressure discretization, respectively. The upwind second-order method was employed to discretize other governing equations. The Eulerian VOF model discretized with the 
Fig. $5 Y^{+}$distribution over the NACA 0012 airfoil at angles of attack of $10^{\circ}$ and $14^{\circ}$
Table 3 Details of the grid cells and $Y^{+}$distribution at $a=10^{\circ}$ and $\operatorname{Re}=3.1 \times 10^{5}$



\begin{tabular}{lllllll}
\hline Grid & Number of cells & Growth factor & $\begin{array}{l}\text { Height of the } \\
\text { first cell }\end{array}$ & Max $Y^{+}$ & Min $Y^{+}$ & Average $Y^{+}$ \\
\hline 1 & 18,000 & 1.1 & $2 \times 10^{-3}$ & 14.13 & 3.42 & 8.14 \\
2 & 32,000 & 1.1 & $1 \times 10^{-4}$ & 6.14 & 0.83 & 2.91 \\
3 & 46,000 & 1.1 & $1 \times 10^{-5}$ & 0.65 & 0.01 & 0.24 \\
4 & 65,000 & 1.1 & $3 \times 10^{-6}$ & 0.61 & 0.01 & 0.22 \\
\hline
\end{tabular}

Table 4 Time step independence study for the dry condition at $\alpha=10^{\circ}$ and $\operatorname{Re}=3.1 \times 10^{5}$

\begin{tabular}{lll}
\hline$C_{L}$ & $C_{D}$ & Time step $(\mathrm{s})$ \\
\hline 0.807 & 0.089 & $5 \times 10^{-3}$ \\
0.822 & 0.081 & $2 \times 10^{-3}$ \\
0.839 & 0.070 & $1 \times 10^{-4}$ \\
0.841 & 0.068 & $1 \times 10^{-5}$ \\
\hline
\end{tabular}

Geo-Reconstruct scheme. The Geo-Reconstruct scheme is able to resolve the sharp interface between the water layer and airflow [36].

A time-domain integral formulation employed wherein time histories of sound pressure, or acoustic signals, at defined receiver locations were directly calculated by measuring few surface integrals. Time accurate solutions can be obtained from unsteady Reynolds-averaged Navier-Stokes (URANS) equations. The convergence value for all equations was set to $10^{-6}$. Furthermore, a time step independence study was done to demonstrate the reliability of the solution which is presented in Table 4. For this purpose, four different time steps were selected to compare lift and drag coefficients in a dry condition at $a=10^{\circ}$. Eventually, it was found that the time step of $1 \times 10^{-4}$ was acceptable for present calculations.
In the present numerical procedure, the injection of rain particles was started at $t=1.85 \mathrm{~s}$ to make sure that the single-phase simulation had reached steady state before injection of rain particles was initiated. We ran all of the simulations for $16 \mathrm{~s}$ to make sure that they all reached a quasi-steady state under rain condition. A total of 300 parcels were injected from the injected line at every flow time step of $1 \times 10^{-4} \mathrm{~s}$ and the number of rain particles in each parcel was such that the desired rainfall rate was maintained.

Figure 6 represents the time histories of lift and drag coefficients at two angles of attack $\left(\alpha=10^{\circ}\right.$ and $\left.16^{\circ}\right)$ at $\operatorname{Re}=3.1 \times 10^{5}$. The plots are displayed for baseline airfoil in dry condition. It was clear that time histories of lift and drag coefficients were repeated in a periodic way for both angles of attack. The final lift and drag coefficients presented throughout the present numerical study were the mean of the values. 
Fig. 6 Time histories of lift and drag coefficients at $a=10^{\circ}$ and $a=16^{\circ}$

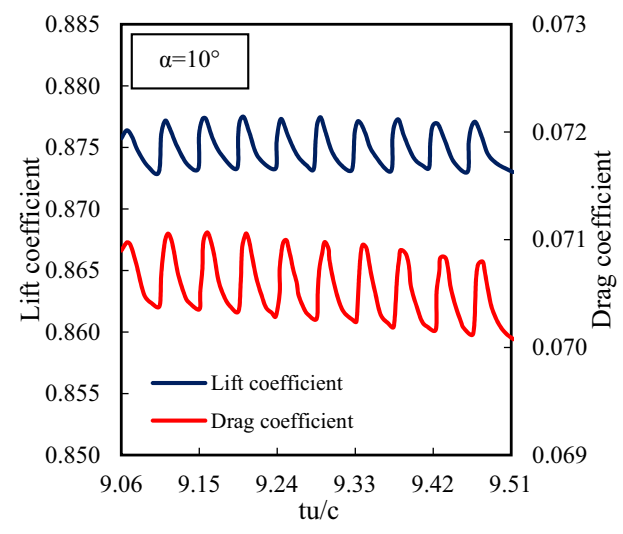

\section{Validation}

In the present study, the computational results of the lift and drag coefficients obtained from CFD simulation
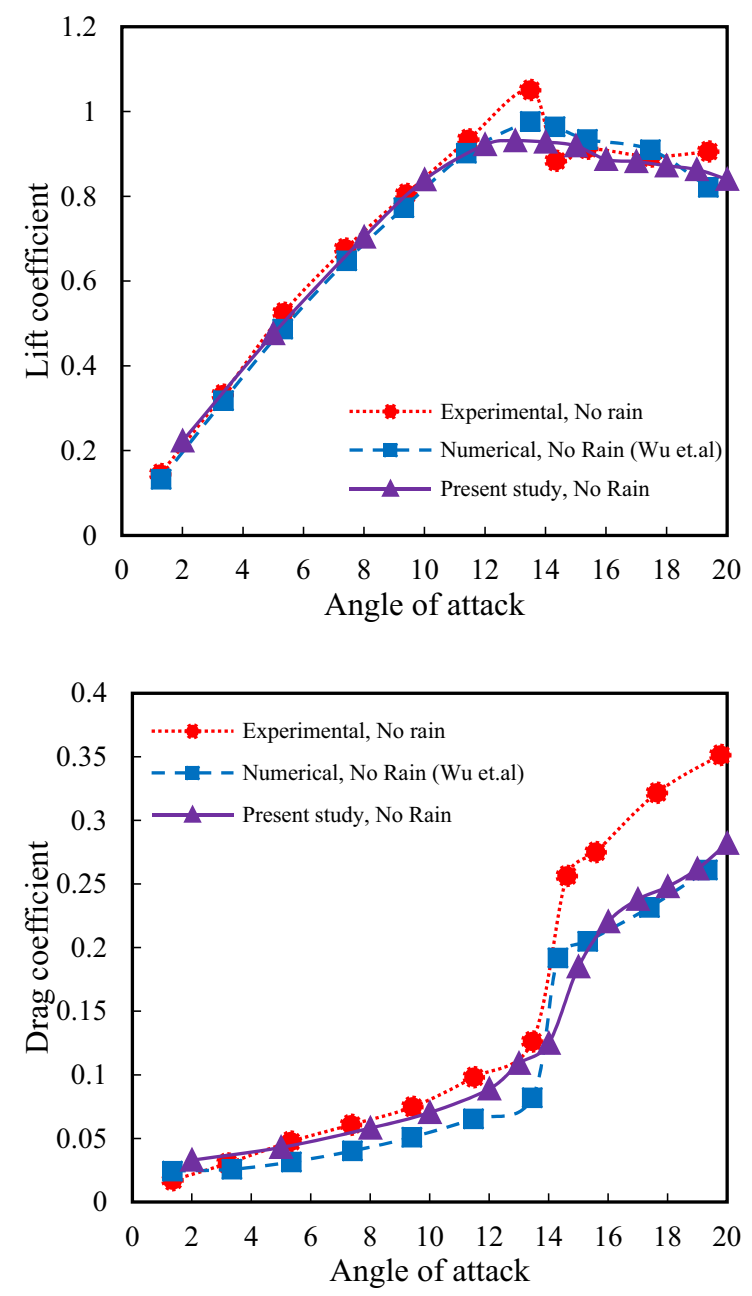

were compared with the available experimental results of Hansman and Craig [37] and numerical results of Wu et al. [3] as shown in Fig. 7. A rain condition of LWC of $30 \mathrm{~g} / \mathrm{m}^{3}$ and a Reynolds number of $3.1 \times 10^{5}$ was selected to be consistent with the experimental results
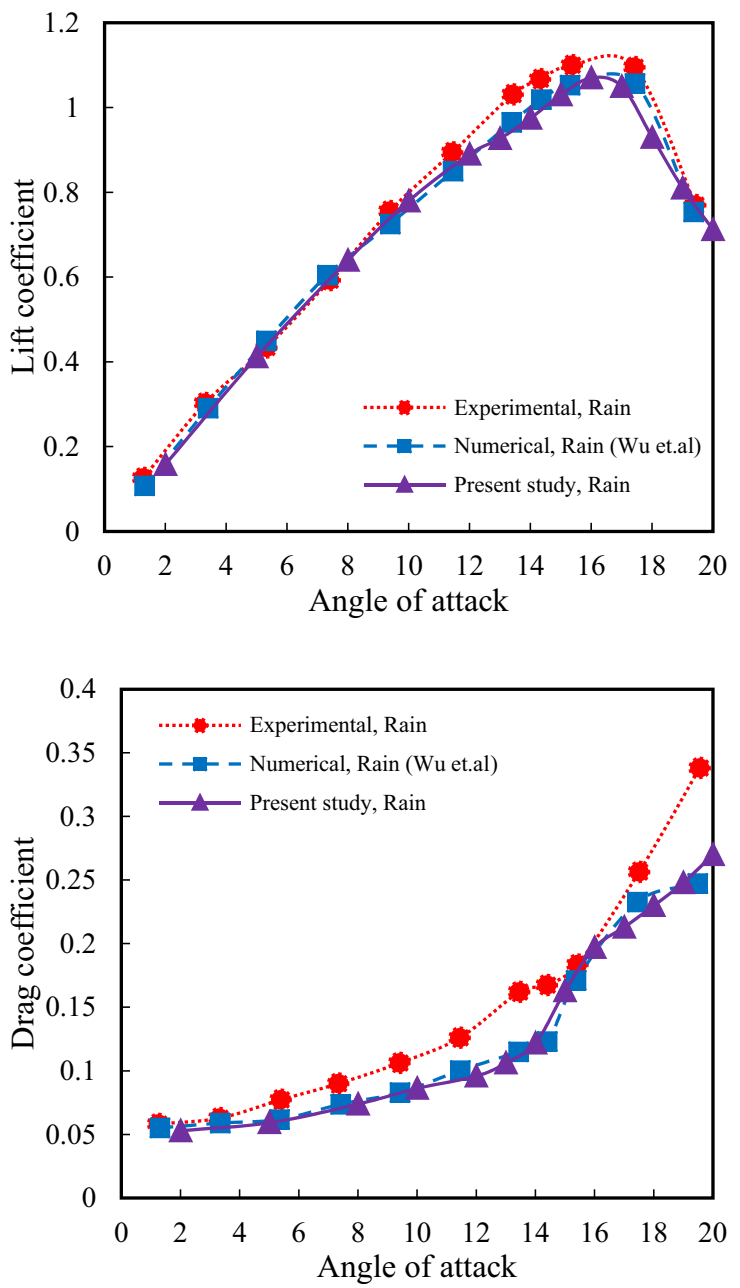

Fig. 7 Comparison between the present computational results and experimental results of Hansman and Craig [37] and the numerical results of Wu et al. [3] 
of Hansman and Craig [37]. It was the only wind-tunnel experiment which was conducted to consider the effects of heavy rain on the aerodynamic performance of NACA 0012 airfoil. It was found that our numerical results had good agreement with the mentioned experimental and numerical results. Therefore, the numerical solving procedure and the applied turbulent model had acceptable accuracy.

Furthermore, the accuracy of the acoustic method applied in the present study was assessed by comparison of sound pressure level predicted from the calculated results against the experimental data of Laratro et al. [38] in Fig. 8. In their study, measurements of the self-noise of NACA 0012 airfoil were measured in an open-jet Anechoic Wind Tunnel at Reynolds number of 96,000 . Due to the lack of experimental and numerical results in rain condition, only the calculated results of the sound pressure level in dry condition were compared to the experimental data of Laratro et al. [38]. A good agreement was achieved between our numerical results and the experimental data.

\section{Results and discussions}

\subsection{Effect of rain on aerodynamic coefficients}

In Fig. 9, the effect of rain on lift and drag coefficients are compared with the results of dry condition in various angles of attack. It was obvious that the lift coefficient decreased while the drag coefficient increased by $60 \%$
Fig. 8 Comparison between the present computational results and experimental results of Laratro et al. [38]
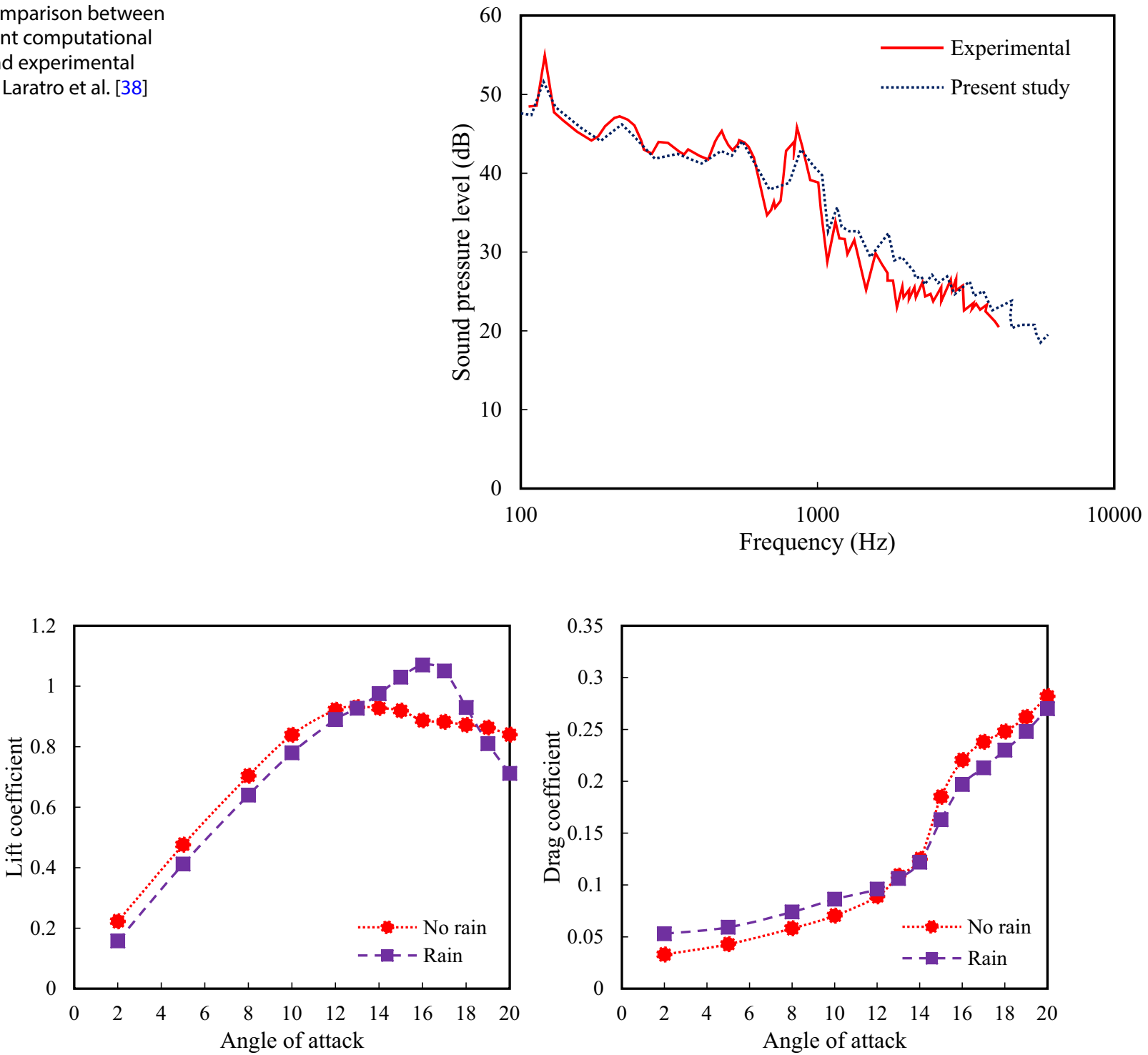

Fig. 9 The effect of rain on lift and drag coefficients at different angles of attack 
at low angles of attack due to heavy rain. The maximum decrease in lift coefficient was $10 \%$ over angles of attack from $2^{\circ}$ to $13^{\circ}$ in the heavy rain condition because of water film formation. In addition, in the present computation results, the stall angle was increased from $13^{\circ}$ in the dry condition to $16^{\circ}$ in the rain condition. This increasing of stall angle is a direct consequence of a premature boundary-layer transition induced by the rain [37], which suppresses stall to be delayed. The behavior of aerodynamic performance of the airfoil was different at low and high angles of attack. As mentioned above, the maximum lift coefficient loss obtained at lower angles of attack, and the degradation in lift decreased as the angle of attack increased. This is due to less water accumulation on the upper surface of the airfoil [36]. Figure 10 represents the lift-to-drag ratio as the airfoil aerodynamic performance for dry and rain conditions. It can be seen that there are significant degradations of the airfoil aerodynamic performance because of water film formation especially at lower angles of attack. The maximum value of lift-to-drag ratio degradation was $56 \%$ at the angle of attack of $2^{\circ}$.

\subsection{Water film height distribution around the airfoil}

The water film height distribution around the airfoil was calculated after simulating heavy rain condition using a two-way momentum coupled Eulerian-Lagrangian approach in the numerical modeling section. The water film height distribution around the airfoil for low and high angles of attack is shown in Fig. 11. The water film height distribution was modeled using the wall film model. The maximum water film height with a magnitude of $3 \mathrm{~mm}$

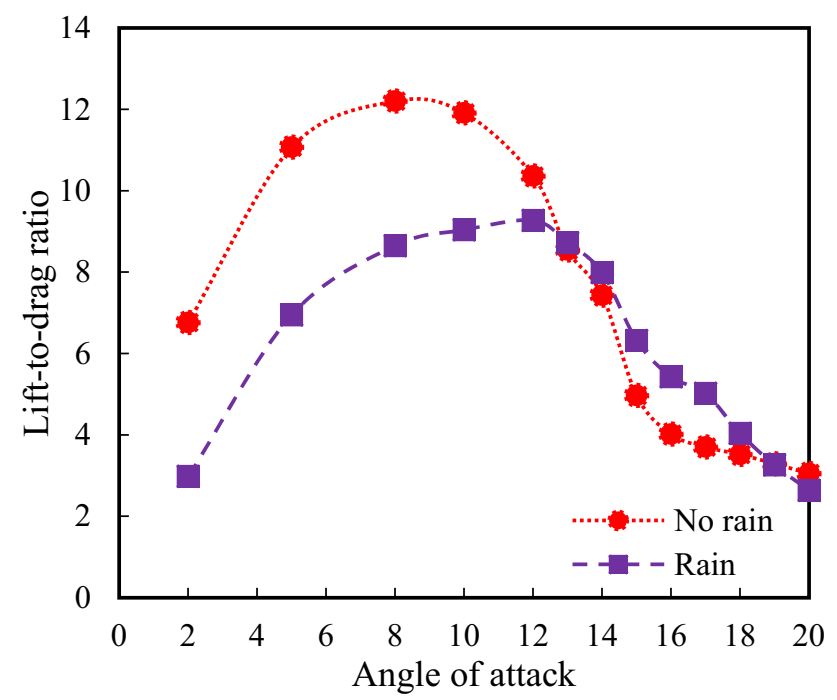

Fig. 10 The effect of rain on the Lift-to-drag ratio at different angles of attack



Fig. 11 Water film height distribution around the airfoil for different angles of attack

appeared at the trailing edge at an angle of attack of $2^{\circ}$. Moreover, by increasing the angle of attack, the maximum height location moved forward to the leading edge of the airfoil. Less water was accumulated on the upper surface of the airfoil by increasing the angle of attack.

\subsection{Effect of rain on the roughness of the airfoil}

Figure 12 illustrates the skin friction coefficient $\left(C_{f}\right)$ of the upper and lower surfaces of the airfoil for three different angles of attack of $2^{\circ}, 10^{\circ}$, and $16^{\circ}$. It was obvious that the roughness of the airfoil had increased as the angle of attack increased. The skin friction coefficient of most positions on the upper and lower surfaces increased due to the concentration of droplets on the airfoil surface and formation of the water film. In addition, most rain droplets impinged on the stagnation point where the maximum roughness of the airfoil was obtained for all angles of attack because of the formation of the uneven water film. Furthermore, there was a slight decrease in the surface roughness on a small portion of the airfoil surfaces which may be due to the function of water lubrication and the lubrication counteracts the effect of roughening [3]. The effect of roughness of the uneven water film mostly caused to increase the drag of the airfoil while the lubrication can improve the aerodynamic performance at some degrees. Additionally, water exerts a higher viscous drag force on the airfoil compared to air, due to its higher viscosity [39]. The water film layer on the airfoil surfaces, splashed-back particles, and particle fog formed on the leading edge of the airfoil are the main reasons for the aerodynamic loss of the airfoil in heavy rain condition. 

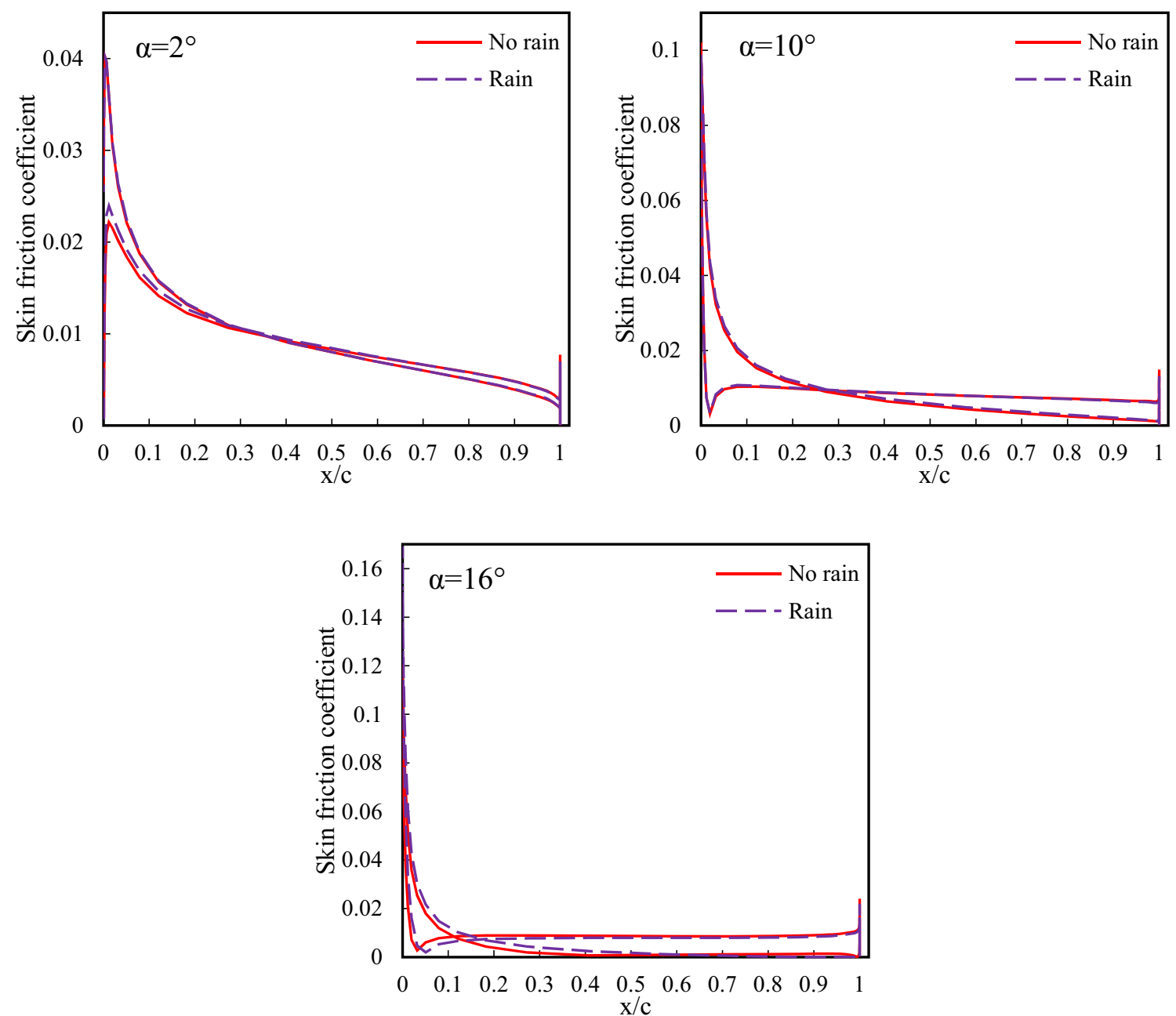

Fig. 12 Skin friction coefficient of the airfoil at different angles of attack

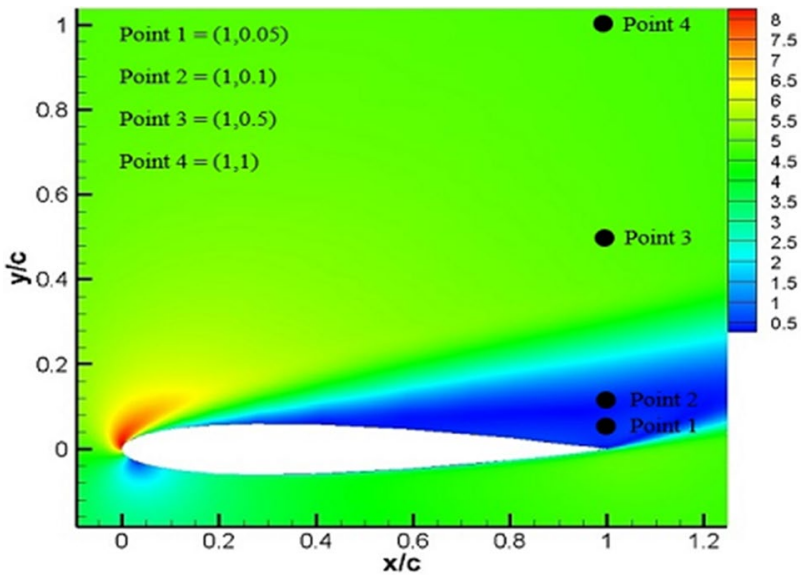

Fig. 13 Receiver points for SPL computation with four locations on the top of the trailing edge displayed on the velocity field $(\mathrm{m} / \mathrm{s})$ at $a=16^{\circ}$

\subsection{Aeroacoustic performance under the rain condition}

Figure 13 shows the receiver points for SPL computation with four locations on the top of the trailing edge which is displayed on the velocity field at $a=16^{\circ}$. A wide range of $0.05 \mathrm{c}$ to $1 \mathrm{c}$ above the trailing edge of the airfoil was selected to evaluate the acoustic performance for both dry and rain conditions. The comparison of predicted sound pressure level spectra generated from NACA 0012 airfoil at four receiver points was illustrated in Fig. 14 for dry and rain conditions. According to this figure, points 1 and 2 are located on the inside wake region and points 3 and 4 are located outside the wake region. As can be seen from these figures, there is a slight decrease in SPL with increasing distance of the receiver from the trailing edge of the airfoil for both dry and rain conditions. Figure 15 shows the comparison of predicted sound pressure level $(\mathrm{SPL})$ spectra at receiver point 3 for angles of attack of $2^{\circ}$, 



Fig. 14 Changes of predicted SPL spectra for $a=16^{\circ}$ and $R e=3.1 \times 10^{5}$ in dry and rain conditions at four different receivers
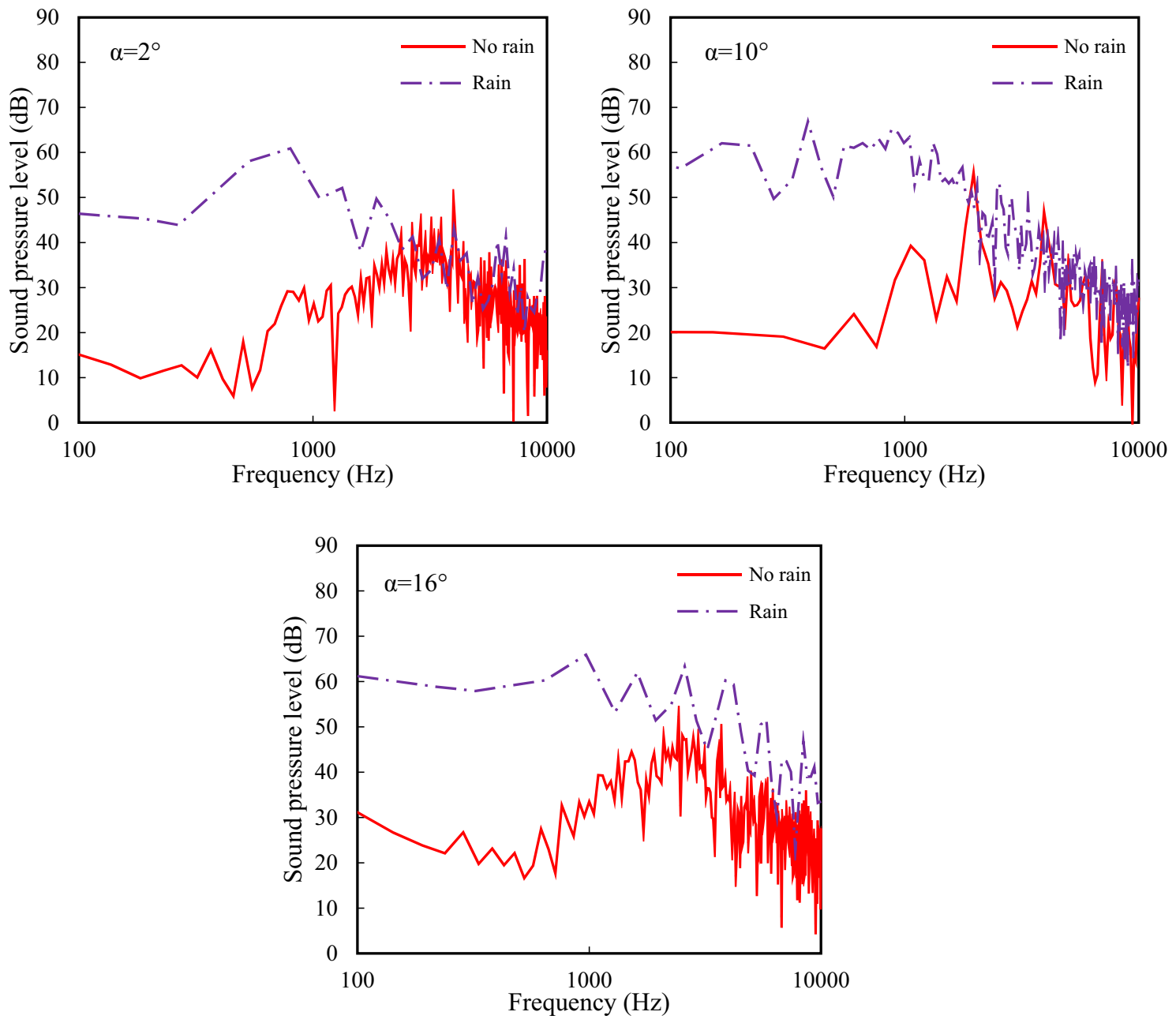

Fig. 15 Comparison of predicted SPL spectra at $\mathrm{Re}=3.1 \times 10^{5}$ in dry and rain conditions at receiver point 3 

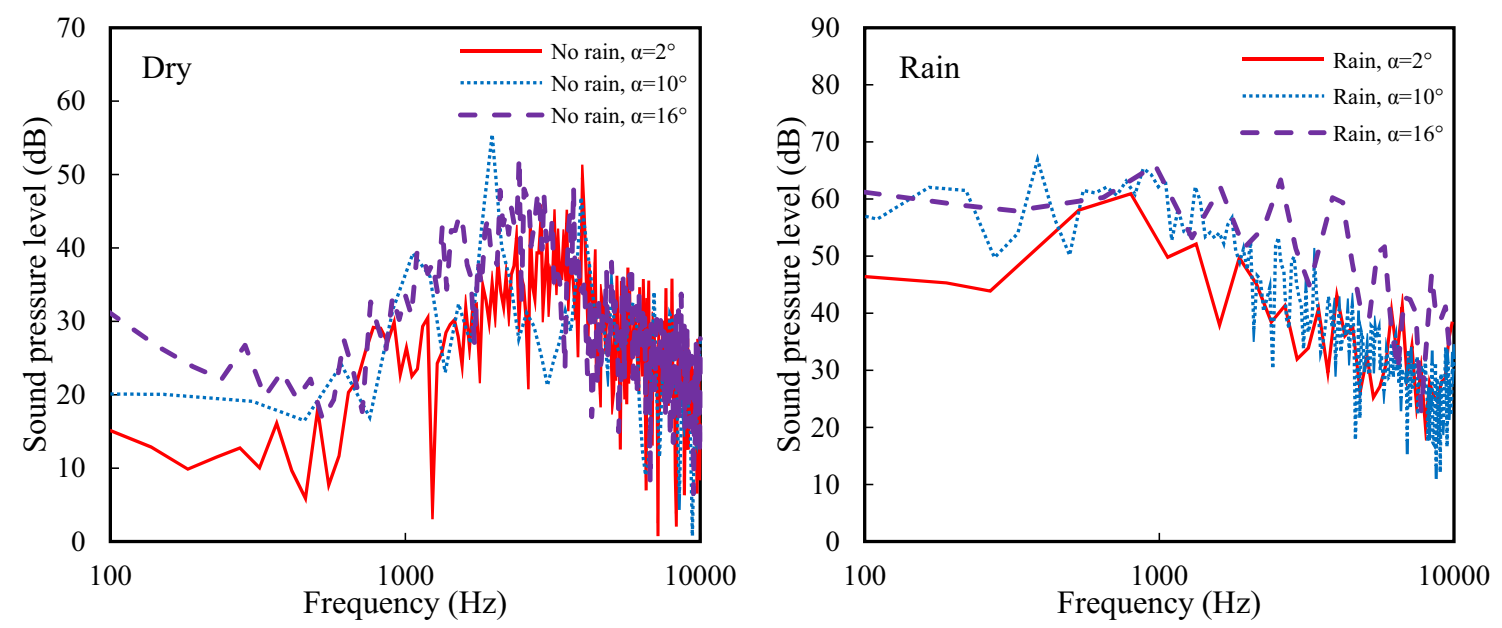

Fig. 16 Comparison of predicted SPL spectra for different angles of attack at $R e=3.1 \times 10^{5}$ in dry and rain conditions

$10^{\circ}$, and $16^{\circ}$ at a Reynolds number of $3.1 \times 10^{5}$ in dry and rain conditions. In these figures, the logarithmic-scaled $x$-axis represents the frequencies in $\mathrm{Hz}$, while the linearscaled $y$-axis represents the sound pressure levels in $\mathrm{dB}$ with the reference pressure of $2 \times 10^{5} \mathrm{~Pa}$ which is equal to the threshold of human hearing. A rain condition of LWC of $30 \mathrm{~g} / \mathrm{m}^{3}$ was selected in order to compute the noise generated in a rain condition. The sound pressure level was computed with a receiver located on the top of the trailing edge. As can be seen from these figures, there is a significant increase in the sound pressure level due to the rain condition. The computation results indicate that the SPL is sensitive to the raindrop impact on airfoil surface and caused to increase sound pressure level, especially in the frequency region less than $2000 \mathrm{~Hz}$. The comparison between sound pressure levels of three different angles of attack at receiver point 3 and various frequencies was presented in Fig. 16. This comparison was done for dry and rain conditions. The sound pressure level increased while the angle of attack increased [17], but this increasing of SPL is more significant in rain condition especially in the high-frequency region higher than $2500 \mathrm{~Hz}$. In rain condition, SPL at an angle of attack of $16^{\circ}$ increased more significantly and various peaks of sound pressure level at different frequencies were observed.

\section{Conclusions}

In the present study, the aerodynamic performance and aeroacoustic mechanism of a NACA 0012 airfoil were numerically investigated via a two-way momentum coupled Eulerian-Lagrangian multiphase approach. This approach was proposed to model the water film layer formation and capture the shape and position of the accumulated water film. In this approach, the continuous air phase was predicted by solving the URANS conservation equations associated with the $k-\varepsilon$ turbulence model and the trajectory of the discrete raindrop phase was predicted by solving the equations of motion for particles in a Lagrangian reference frame. In addition, the present simulation utilized the Ffowcs Williams-Hawkings (FW-H) method to predict the aerodynamic noise of the airfoil in a heavy rain condition. The aerodynamics coefficients were compared to the experimental results of Hansman and Craig [37] and numerical results of Wu et al. [3] in a Reynolds number of $3.1 \times 10^{5}$ and a rain condition of LWC of $30 \mathrm{~g} / \mathrm{m}^{3}$. A good agreement was achieved with the present results and mentioned experimental and numerical results. The results showed a considerable aerodynamic loss of the airfoil in a heavy rain condition. The maximum decrease of lift coefficient obtained about $10 \%$ while the drag coefficient increased up to $60 \%$ at low angles of attack due to the heavy rain. The maximum value of liftto-drag ratio degradation was obtained $56 \%$ at an angle of attack of $2^{\circ}$. The stall was increased up to $3^{\circ}$ which was suppressed by the premature boundary-layer transition. Furthermore, by applying the Ffowcs Williams-Hawkings (FW-H) method, generated noises of the airfoil in both dry and rain condition were successfully computed and good agreement was obtained compared to the experimental data of Laratro et al. [38] It was concluded that sound pressure level increased due to the rain condition. The SPL was so sensitive to the raindrop impact on airfoil surface and caused to increase sound pressure level especially in the frequency region less than $2000 \mathrm{~Hz}$. By increasing the 
angle of attack, the SPL increased especially in the highfrequency region higher than $2500 \mathrm{~Hz}$ in rain condition. In overall, two complex physical phenomena have been completely modeled and studied to measure aerodynamic degradation and aeroacoustic mechanism of the airfoil in dry and heavy rain conditions. Computational results of the present study could be useful for aircraft designers to decrease the aerodynamic penalties and aircraft accidents in rain condition with a special focus on understanding the effect of this atmospheric condition on the production of noise in airports. Because rain is a common phenomenon in many areas of the world.

\section{Compliance with ethical standards}

Conflict of interests No conflict of interest was declared by the authors.

\section{References}

1. Haines $P$, Luers J (1983) Aerodynamic penalties of heavy rain on landing airplanes. J Aircr 20:111-119

2. Cao Y, Wu Z, Xu Z (2014) Effects of rainfall on aircraft aerodynamics. Prog Aerosp Sci 71:85-127

3. Wu Z, Cao Y (2015) Numerical simulation of flow over an airfoil in heavy rain via a two-way coupled Eulerian-Lagrangian approach. Int J Multiphas Flow 69:81-92

4. Yarin AL (2006) Drop impact dynamics: splashing, spreading, receding, bouncing.... Annu Rev Fluid Mech 38:159-192

5. García-Magariño A, Sor S, Velazquez A (2015) Experimental characterization of water droplet deformation and breakup in the vicinity of a moving airfoil. Aerosp Sci Technol 45:490-500

6. Sor S, García-Magariño A, Velazquez A (2016) Model to predict water droplet trajectories in the flow past an airfoil. Aerosp Sci Technol 58:26-35

7. Rhode RV (1941) Some effects of rainfall on flight of airplanes and on instrument indications. No. NACA-TN-803. National Aeronautics and Space Admin Langley Research Center Hampton VA.

8. Luers JK, Haines PA (1983) Experimental measurements of rain effects on aircraft aerodynamics. In AIAA 21st Aerospace Sciences Meeting.

9. Luers J, Haines $P$ (1983) Heavy rain influence on airplane accidents. J Aircr 20:187-191

10. Wan T, Wu SW (2004) Aerodynamic analysis under influence of heavy rain. J Aeronaut Astronaut Aviat 41:173-180

11. Wu Z, Cao Y, Ismail M (2013) Numerical simulation of airfoil aerodynamic penalties and mechanisms in heavy rain. Int. J. Aerosp, Eng

12. Ismail M, Yihua C, Bakar A, Wu Z (2014) Aerodynamic efficiency study of $2 D$ airfoils and $3 D$ rectangular wing in heavy rain via two-phase flow approach. P I Mech Eng G-J Aer 228:1141-1155

13. Wu Z (2018) Drop "impact" on an airfoil surface. Adv Colloid Interfac 256:23-47

14. Jackson BR, Dakka SM (2018) Computational fluid dynamics investigation into flow behavior and acoustic mechanisms at the trailing edge of an airfoil. Noise Vib Worldwide 49:20-31
15. Brooks TF, Pope DS, Marcolini MA (1989) Airfoil self-noise and prediction: Technical report, NASA reference publication 1218. NASA, Washington, DC

16. Singer BA, Brentner KS, Lockard DP, Lilley GM (2000) Simulation of acoustic scattering from a trailing edge. J Sound Vib 230:541-560

17. Shen WZ, Zhu W, Sorensen JN (2009) Aeroacoustic computations for turbulent airfoil flows. AIAA J 47:1518-1527

18. Ghasemian M, Nejat A (2015) Aerodynamic noise computation of the flow field around NACA 0012 airfoil using large eddy simulation and acoustic analogy. J Comput Appl Mech 46:41-50

19. Ffowcs Williams JE, Hawkings DL (1969) Sound generation by turbulence and surfaces in arbitrary motion. Phil Trans R Soc Lond A 264:321-342

20. Apte SV, Gorokhovski M, Moin P (2003) LES of atomizing spray with stochastic modeling of secondary breakup. Int J Multiphas Flow 29:1503-1522

21. Bezos GM, Dunham Jr RE, Gentry Jr GL, Melson Jr WE (1992) Wind tunnel aerodynamic characteristics of a transport-type airfoil in a simulated heavy rain environment. Technical Report: TP-3184, NASA.

22. Markowitz AH (1976) Raindrop size distribution expressions. J Appl Meteorol 15:1029-1031

23. Wu Z, Cao Y, Nie S, Yang Y (2017) Effects of rain on vertical axis wind turbine performance. J Wind Eng Ind Aerod 170:128-140

24. Fatahian H, Salarian H, Nimvari ME, Khaleghinia J (2020) Computational fluid dynamics simulation of aerodynamic performance and flow separation by single element and slatted airfoils under rainfall conditions. Appl Math Model 83:683-702

25. Fatahian H, Salarian H, Nimvari ME, Khaleghinia J (2020) Effect of Gurney flap on flow separation and aerodynamic performance of an airfoil under rain and icing conditions. Acta Mech Sinica. https://doi.org/10.1007/s10409-020-00938-3

26. Wu Z, Cao Y, Ismail M (2015) Heavy rain effects on aircraft longitudinal stability and control determined from numerical simulation data. P I Mech Eng G-J Aer 229:1824-1842

27. Raj LP, Lee JW, Myong RS (2019) Ice accretion and aerodynamic effects on a multi-element airfoil under SLD icing conditions. Aerosp Sci Technol 85:320-333

28. Versteeg HK, Malalasekera W (2007) An introduction to computational fluid dynamics: the finite volume method. Pearson education.

29. Han Z, Xu Z, Trigui N (2000) Spray/wall interaction models for multidimensional engine simulation. Int J Engine Res 1:127-146

30. Bilanin AJ (1987) Scaling laws for testing airfoils under heavy rainfall. J Aircr 24:31-37

31. Morsi SAJ, Alexander AJ (1972) An investigation of particle trajectories in two-phase flow systems. J Fluid Mech 55:193-208

32. Plogmann B, Herrig A, Würz W (2013) Experimental investigations of a trailing edge noise feedback mechanism on a NACA 0012 airfoil. Exp Fluids 54:1480

33. Lighthill MJ (1952) On sound generated aerodynamically I. General theory. Proc R Soc Lond A 211:564-587

34. Caridi D (2008) Industrial CFD simulation of aerodynamic noise (Doctoral dissertation, Università degli Studi di Napoli Federico II).

35. Farassat F, Succi GP (1982) The prediction of helicopter rotor discrete frequency noise. In American Helicopter Society, Annual Forum, 38th, Anaheim, CA, May 4-7, 1982, Proceedings (A8240505 20-01) Washington, DC, American Helicopter Society, (pp. 497-507).

36. Cai M, Abbasi E, Arastoopour H (2012) Analysis of the performance of a wind-turbine airfoil under heavy-rain conditions 
using a multiphase computational fluid dynamics approach. Ind Eng Chem Res 52:3266-3275

37. Hansman RJ, Craig AP (1987) Low Reynolds number tests of NACA 64-210, NACA 0012, and Wortmann FX67-K170 airfoils in rain. J Aircr 24:559-566

38. Laratro A, Arjomandi M, Cazzolato B, Kelso R (2017) Self-noise of NACA 0012 and NACA 0021 aerofoils at the onset of stall. Int J Aeroacoust 16:181-195
39. Cohan AC, Arastoopour H (2016) Numerical simulation and analysis of the effect of rain and surface property on wind-turbine airfoil performance. Int J Multiphas Flow 81:46-53

Publisher's Note Springer Nature remains neutral with regard to jurisdictional claims in published maps and institutional affiliations. 